\title{
EDUCAR E CUIDAR DO CORPO: BIOPOLÍTICA NO ATENDIMENTO À PEQUENA INFÂNCIA'
}

\author{
Ana Cristina Richter* \\ Alexandre Fernandes Vaz**
}

RESUMO: Partindo de uma pesquisa de abordagem etnográfica realizada em um ambiente educacional de atendimento à pequena infância, o presente trabalho trata de dispositivos pedagógicos que transpassam o corpo nos momentos de higiene e nos demais tempos que compõem a rotina das instituições de educação infantil. Os resultados revelam discursos e ações que se dirigem à cultura de uma infância asséptica já presente nas concepções higienistas do século XIX. Os momentos que conformam a rotina institucional se fazem fortemente marcados pela presença de ações e estratégias vinculadas à higiene, à saúde e à "qualidade de vida". Os discursos e práticas que ali circulam aparecem em meio a um conjunto de normas que funcionam como braço pedagógico de uma biopolítica que atua na constituição da vida nua.

Palavras-chave: Educação Infantil; Biopolítica; Biopolítica da Infância; Higienismo.

\section{EDUCATION AND BODY CARE: BIOPOLITICS IN CHILDCARE}

ABSTRACT: Through an ethnographic research in a Kindergarten, this paper aims to study the pedagogical axes that cross the body in its moments of hygiene and other moments of institutional routine towards children education. The results show discourses and actions concerning the culture of an "aseptic childhood", already present in the hygienic conceptions of the XIX Century. The stations of institutional routine are conformed by actions and strategies aimed at hygiene, health and "life quality". Such discourses and practices are amongst a set of norms working as a pedagogic arm of the biopolitics acting in the constitution of a nude life.

Keywords: Kindergarten; Biopolitics; Biopolitics of Childhood; Hygiene.

\footnotetext{
* Doutoranda em Educação pela Universidade Federal do Paraná (PPGE/UFPR/CAPES); Membro do Núcleo de Estudos Educação e Sociedade Contemporânea (CED/UFSC/CNPq). E-mail: ana_tinaa@uol.com.br

* Doutor em Ciências Humanas e Sociais pela Leibnis Universität Hannover, Alemanha; Professor da Universidade Federal de Santa Catarina (UFSC); Coordenador do Núcleo de Estudos e Pesquisas Educação e Sociedade Contemporânea (CED/UFSC/CNPq); Pesquisador CNPq).E-mail: alexfvaz@pq.cnpq.br
} 


\section{Introdução}

Analisando o trabalho de Hannah Arendt ${ }^{2}$, Giorgio Agamben (2004, p. 130) afirma que a base da democracia moderna "não é o homem livre com suas prerrogativas e os seus estatutos, e nem simplesmente o bomo, mas corpus é o novo sujeito da política...”. A vida qualificada como bíos, distinguida pelo discurso, é substituída não pela zoé, condição de natureza não-qualificada, mas pela vida nua (AGAMBEN, 2004), vida desqualificada como natureza.

Esse mesmo glossário, que, no século XX, encontra uma de suas formas na racionalidade médico-higienista, compôs o processo de desenvolvimento da sociedade brasileira em sua utopia modernizadora: orientada ao progresso, urbanizada, desenvolvida, limpa, sadia, enfim, civilizada. Se, num primeiro momento, as elites participaram desse processo sob as orientações/determinações médicas, num segundo, também os "semfamília", os ambulantes, os criados, os pivetes, os analfabetos, as mulheres menos abastadas e suas crianças, todos se tornaram alvo de políticas e discursos higienistas em prol da assepsia dos espaços urbanos e das condutas humanas (COSTA, 1999).

A historiografia da educação ensina que o senhorio da família sobre as crianças passava a ser orientado pelos educadores expertos higienistas, juntando-se a eles os juristas e os filantropos, legisladores das normas e preceitos morais a serem incorporados e reproduzidos pelos pequenos, criando, assim, uma "consciência", a partir de predicados que garantissem o autocontrole e os cuidados de si, que também auxiliariam a produzir mão de obra e a encobrir as injustiças sociais, a miséria. Era preciso "salvar" a vida dos "infelizes abandonados", mentes que se supunha doentes $^{3}$, por meio das "receitas" prescritas pelos higienistas. Esses agente-educadores dedicaram especial atenção às crianças ao almejarem a transformação dos pequenos no homem digno do amanhã - o que contribuiria para a melhoria da sociedade e, sobretudo, da espécie (GONDRA, 2000).

Também as instituições de atendimento à infância constituíramse, ao longo da história, como territórios que deveriam produzir sujeitos "normais", disciplinados, assépticos, saudáveis, autogovernados (GONDRA, 2000; KUHLMANN Jr., 1998). Os corpos infantis são ainda hoje conduzidos ao interior de instituições, as creches e núcleos de educação 
infantil, ambientes que contribuíram e contribuem para a aprendizagem do autocontrole e da autoconservação física, assim como para aqueles processos biológicos de conjunto que respondem pela gestão da população e têm como propósito o incremento da vida.

Tendo como material parte dos resultados de uma pesquisa etnográfica em uma creche da Rede Pública de Ensino de Florianópolis, composta por 38 profissionais que atendem 180 crianças entre 0 e $(5)^{4} 6$ anos de idade, temos o propósito de brevemente apontar a presença e a atualização de discursos e estratégias higienistas operando na educação da pequena infância e, dessa forma, atuando como braço pedagógico de uma produção biopolítica ${ }^{5}$ da infância. A pesquisa que deu origem ao presente artigo considerou espaços e tempos da educação do corpo no âmbito de uma rotina organizada por momentos: entrada, saída, alimentação, sono, parque, atividade orientada, higiene e, no caso da creche em questão, de Educação Física, visto que a rede de ensino da localidade oferece essas aulas desde o berçário. Neste texto, oferecemos relevo aos momentos de higiene, considerados pela instituição, tal como os demais períodos que compõem a rotina, como espaço/tempo de cuidado e educação dos pequenos. No entanto, não deixamos de dialogar com os demais períodos que compõem o dia a dia da creche, uma vez que estes aparecem fortemente marcados pela presença de ações e estratégias vinculadas à higiene, a saúde, à "qualidade de vida". Focalizaremos, para tal, cenas extraídas de nosso caderno de campo, trechos de documentos analisados, bem como vozes de atores institucionais captadas por meio de entrevistas.

Inicialmente, apresentamos algumas questões referentes ao esforço sócio-sanitário presente na educação infantil, mas também contido nos pressupostos da Declaração dos Direitos das Crianças e em alguns outros documentos voltados à infância. Esses saberes adentram e circulam nesse ambiente educacional e se materializam nas vozes de seus atores, mas também nas linhas que compõem seu Projeto Político Pedagógico. Em seguida tratamos dos Momentos de Higiene e de outros tempos que compõem a rotina institucional, por meio de recortes de cenas extraídas de nosso diário de campo. Esses períodos aparecem atravessados por estratégias e prescrições ligadas à "neutralização" da sujeira (e da miséria), mas também da infância - lugar temporal de "incertezas" e "incompletude" - e seus "desajustes". Concluímos o texto apontando algumas relações entre uma pedagogia que se vale (e atualiza) estratégias 
e discursos higienistas e uma biopolitica que atua no âmbito da vida nua, potencializando, em sentido muito preciso, o corpo e a vida.

\section{Higiene, saúde e qualidade de vida:}

\section{breve passagem por documentos, planos, projetos, entrevistas e outros escritos}

No que se refere à Educação Básica, os Parâmetros Curriculares Nacionais sugerem que a saúde deva ser abordada como tema transversal no cotidiano e no decorrer de todas as atividades no interior dos ambientes educacionais. O documento destaca a importância de "prevenir e remediar" atitudes que possam prejudicar o desenvolvimento da "cidade saudável", da "comunidade forte, solidária e constituída sobre bases de justiça social”, além da criação de um ambiente favorável à qualidade de vida: limpo, seguro e "que satisfaça as necessidades básicas" (BRASIL, 2000 citado por COOPER; SAYD, 2006, p. 187). Também nos Referenciais Curriculares Nacionais para Educação Infantil, encontramos diversas passagens relacionadas aos cuidados para com os pequenos e que se referem, entre outros aspectos, à segurança, à proteção, à saúde e à alimentação (RCNEI, 1998, p. 18). Ou, ainda, à organização do tempo de trabalho que envolve atividades de repouso, alimentação e higiene (RCNEI, 1998, p. 73), observando que o desenvolvimento integral das crianças depende de cuidados relacionais e "dos cuidados com os aspectos biológicos do corpo, como a qualidade da alimentação e dos cuidados com a saúde" (RCNEI, 1998, p. 24). O documento destaca que os "procedimentos de cuidado também precisam seguir os princípios de promoção da saúde" (RCNEI, 1998, p. 25), considerando tanto a organização do ambiente, os cuidados com a ventilação, insolação, segurança, conforto, estética e higiene dos espaços e dos objetos, quanto a segurança, o conforto e a proteção da criança para que ela se desenvolva e "aprenda procedimentos que valorizem seu bem-estar” (RCNEI, 1998, p. 51).

Esses elementos encontram-se presentes nos documentos da creche pesquisada e também são abordados em palestras oferecidas aos familiares dos pequenos frequentadores da instituição. Além disso, nas reuniões de estudo, o tema da saúde e da higiene tem lugar privilegiado.

Não apenas nos documentos atuais, mas já no projeto de implementação dos primeiros núcleos de educação infantil e creches públicas 
da cidade de Florianópolis, elaborado por profissionais da saúde, da assistência social e da educação, aparecem objetivos relacionados à ordem e ao asseio, como medidas de combate à carência econômica, à falta de higiene, à desnutrição e aos descuidos com a saúde (OSTET'TO, 2000). Em uma pasta contendo documentos relativos a 1982, ano de fundação da creche, encontra-se em destaque, entre os objetivos da instituição, a busca por estabelecer hábitos de vida saudáveis em relação à higiene, à recreação e ao sono.

Nos textos, mas também nas vozes e nas ações profissionais, a higiene ocupa relevo, como se pode observar nas falas a seguir:

Estou em paz porque ali está limpo, [...] a limpeza em primeiro lugar. Como é que diz o ditado? A limpeza é Deus, é amor. A sujeira o diabo carregou: o diabo gosta de onde está sujo, onde transmite doença. A pessoa pode ser pobre, mas estando tudo limpo, se ganha a paz. (Servente)

A gente faz cursos de manipulação de alimentos, onde se aprende desde tu receberes o alimento até a hora de servir. A primeira coisa é o prazo de validade. (Houve um curso em que) fizeram uma encenação para ver se tu és Maria ou se tu és Joana. Joana é caprichosa e a Maria é uma relaxadona. Ela vai abrir a lata e mete a faca. [...] Pode estar suja. [...] O correto é pegar o abridor; primeiro lavar em cima. (Merendeira)

Encontramos, assim, um conjunto de registros que compreendem diferentes formas de circulação de saberes relativos à higiene e que adentram a creche, seja por meios formais, como os cursos de manipulação de alimentos, seja por meio de valores religiosos e da propaganda oficial acessada pela memória televisiva: em entrevista, um servente relembra a imagem do Sujismundo - lançada em 1972, em campanha nacional do governo federal: "Povo desenvolvido é povo limpo" -, aquele que lançava papel ao chão, não tomava banho e permanecia rodeado por mosquitos.

Se nos inícios do Moderno era preciso educar as condutas e estimular hábitos salutares, tal como a limpeza do corpo e da casa, essas normas parecem exigir hoje um grau menor de coerção externa, dada sua introjeção, autorregulação e interiorização normativa (ELIAS, 1994). No entanto, hodiernamente, deparamo-nos com outras formas de tutelagem dos corpos, dos sentidos, das condutas individuais e coletivas, relacionadas à higiene, à saúde, à qualidade de vida. A vida, ao livrar-se da sujeira, 
da imundície, da infecção, da contaminação, dos "sujismundos", deve agora contrair qualidade. Esta, racionalmente organizada, compreende atributos, padrões e estilos que sugerem modelos "saudáveis" e "normais" associados ao consumo: não basta banhar o corpo, é preciso adquirir um produto predeterminado - fármacos, técnicas, cosméticos, fantasias para que o "evento" se cumpra com qualidade. Ou seja, uma série de normas ${ }^{6}$ coloca-se a serviço da vida, divulgando características constitutivas e determinantes daquela qualidade. Alicerçadas pelos saberes cientificistas, essas normas circulam nas revistas, nos outdoors, nas propagandas e nos programas televisivos estrelados por especialistas, atores ou quaisquer outros intérpretes que atuam como representantes daquele receituário de qualificação despolitizadora do corpo e da vida ${ }^{7}$.

O próprio termo "qualidade de vida" aparece ancorado em dados estatísticos e é propalado pelo Estado, por empresas, sindicatos, ONGs, Igrejas, especialistas e escolas, tornando-se, segundo Oliveira (2003, p. 99), "condição para (se) fazer parte da sociedade cidadã, emancipada, consciente, crítica, civilizada, tolerante, segura”. A qualidade de vida "pode" ser adquirida na compra de uma casa, de um creme facial, na prática regular de atividades físicas, no consumo de determinados produtos alimentícios, na aquisição de um plano de saúde. Está vinculada ao labor e ao tempo livre, à "gestão de pessoas" nas empresas "amigas das crianças" e nas corporações de "qualidade total"; atrela-se à ISO, que tem seu carimbo estampado nas embalagens de infindas mercadorias; está acoplada à frequência na academia de ginástica, à venda da margarina e do colchão que fornece atributos ao sono e aos sonhos.

Essa fisionomia determinada pela "qualidade de vida" alcança forma na lei e, confundindo-se com a vida (vida simplesmente vivente), cria um universal homogêneo e, ao mesmo tempo, uma repugnância ao nãoigual. A aversão ao diferente, ao desviante, ao não-igual corresponde àquela mesma intrusão de princípios biológico-científicos na ordem política, a exemplo da eugenia nacional-socialista, ao extirpar a "vida indigna de ser vivida": a dos judeus eliminados como piolhos ${ }^{8}$, vida nua. O diverso (o outro, agora visto como inimigo) cumpre o papel de paciente ou cadáver e, como lembra Adorno (1993, p. 48), "ele não é mais do que um mero objeto de medidas técnico-administrativas".

O "interesse pela saúde" e pela "qualidade de vida" da infância pode ser também encontrado na Convenção dos Direitos das Crianças e 
no Estatuto da Criança e do Adolescente. Ambos dispõem sobre o direito à vida, à saúde, à educação, a medicamentos e próteses, ao esporte e ao lazer, entre outros aspectos. Temos ainda as empresas, o presidente e os prefeitos "amigos das crianças", compondo o programa pela qualidade de vida de uma infância saudável. A "perspectiva concreta de uma cidade melhor" por meio do desenvolvimento da criança com "saúde, educação e qualidade de vida" recoloca o "trato" da infância como investimento econômico em defesa da sociedade, de modo análogo aos Parâmetros Curriculares Nacionais, que também procuram contribuir para a construção da "cidade saudável". Programas, parâmetros, campanhas e ações "amigas das crianças" adotam procedimentos para cuidar dos pequenos e, ao mesmo tempo, reforçam a naturalização de sua condição social: os excluídos também devem ser higienizados. Isso nos faz retornar aos modelos higienistas dos séculos passados, que prometiam um melhor "porvir" a partir da produção de uma "infância devidamente higienizada, mesmo que tal estratégia produzisse, legitimasse e terminasse por naturalizar as desigualdades sociais" (GONDRA, 2000, p. 116).

Um extenso conjunto de dados, vozes, textos, estatutos, selos e emblemas, na indistinção entre norma e vida biológica, se interpenetram, adentram também a creche e nela são interpretados, aplicados e transformados, auxiliando a dar forma às identidades profissionais e ao trabalho dos diferentes atores institucionais e, ao mesmo tempo, a organizar a infância e seus "desajustes", "descontroles" e "inabilidade". Ou, de outro modo, a transferir, gradualmente, a responsabilidade aos "pequenos futuros cidadãos" pela sua própria saúde, potência e qualidade da/na vida - conforme veremos a seguir.

\section{Momentos de higiene:}

\section{técnicas de embelezamento, cuidado de si, alto rendimento, performance e consumo como norma}

Os períodos específicos de limpeza dos corpos, os Momentos de Higiene, ocorrem na creche em oito ocasiões diárias, sempre antecedendo e sucedendo os tempos destinados às práticas alimentares: lanche da manhã e da tarde, almoço, jantar. As cenas que seguem indicam os cuidados com o corpo nesses períodos. 
CENA 1: A professora pega um menino no colo e dirige-se ao banheiro. Na banheira ao lado, outra professora banha uma menina por completo, pois: "Vem podre de casa e todo dia a gente dá banho nela". O garoto, agora limpo, recebe outros cuidados. A professora seca-o, passa uma pomada para assaduras e talco e coloca-lhe a fralda. Enquanto isso, na sala, a auxiliar troca outra criança. $\mathrm{O}$ movimento se repete até que todas as crianças tenham sido trocadas. "Às vezes, quando eles estão muito sujos porque não tomam banho em casa, a gente aproveita e põe na banheira", diz uma professora.

CENA 2: As crianças sentam-se recostadas junto à parede, aguardando a entrega da escova dental. No banheiro escuro, escuta-se: "Tira a espuma da boca", "Não leva a escova pro bacio", "Deu”, “Opa! Quem foi que deu o arroto?" A professora acompanha uma menina e a coloca em frente ao espelho, indicando o modo correto de escovação. Segue-se então: "Anda, escova", "Aqui embaixo, várias vezes", "Lava a boca e a mão", "Lava com sabonete" [...] Ainda durante a escovação, ouve-se: "Deu", "Molha a escova", "Anda", "Deu", "Vai" Uma criança se aproxima e mostra sua mochila: "Olha minha mochila da Barbie".

CENA 3: As crianças fazem cambalhotas enquanto a professora auxilia na escovação dos dentes. Pela porta de acesso, esta espia a sala. Diz: "Deixa. Vem. Vai escovar", "Mauro, no teu lugar. Que coisa teimosa". Um menino guarda seus tênis junto à mochila, comentando: "Ó meu tênis do Batman". A professora coloca pasta dental sobre as escovas. Entrega às crianças, encaminhando-as às pias do banheiro. Logo vai dizendo: "Anda", "Ligeiro", "Sem palhaçada". Chama outras crianças e pede: "Lava a boca, lava a boca que tá suja", "Pega o bico".

CENA 4: Da auxiliar escuta-se: "Calça sapato", "Quero a mão lavada direito", "Vai secar o peito", "Puxa da mão dele a escova", "Teu pescoço tá um nojo. Vai lá lavar". Às 16h40, a professora senta-se numa das cadeirinhas da sala. À sua frente, encontram-se pentes e escovas. Uma a uma as crianças sentam em seu colo e têm seus cabelos escovados. Algumas meninas são enfeitadas com laços e pregadores. 
As professoras e as auxiliares pedem às crianças: "Vai lavar o pescoço que está um nojo", "lava a boca", "limpa o nariz”, "puxa a descarga", "lava a mão", "lava bem que está sujo", entre outras inúmeras ordenações diárias e persistentes. Também elas banham aquela criança que "veio suja", que "vem podre de casa", que "fez uma cagança", conforme costumam anunciar. Procuram eliminar os cheiros e os vestígios trazidos do lar. Só então se torna possível estabelecer outro contato: beijar, abraçar, elogiar a limpeza e a moralidade dos costumes nos corpos assépticos.

Essas ações parecem compor um conjunto de processos sóciosanitários (MINAYO, 2006) ligados à neutralização da sujeira, da doença (e da miséria) e à neutralização da infância e seus desajustes, conforme apontáramos anteriormente, que procuram tornar as crianças capazes de gerir seu próprio corpo por meio da aprendizagem do autocontrole. O esforço em entregar aos pequenos a gestão do próprio corpo parece estar integrado à sociedade esportivizada, na qual a performance - impregnada pelos princípios de alto rendimento e aptidão física - ganha destaque: o corpo é treinado no intuito da maximização, da superação dos limites, tornando-se "craque" ao ascender às normas da civilidade centralizadas no saber-fazer.

A cada momento de higiene, as palavras "deu", "anda", "rápido", “daqui a pouco o pai chega", "depressa", "vai logo" ecoam à porta do banheiro. Todo esse veloz empreendimento associa-se à melhor performance funcional a partir da aquisição de gestos técnicos influenciados pela necessidade de coordenar ações que visam a incitar à saúde. A capacitação para executar tarefas de forma eficiente ou a exclusão das incapacidades funcionais aparece nas vozes dos/das profissionais como princípios de "autonomia": solução de tarefas previamente designadas, "fazer sozinho", mesmo que para tal não se coloque a exigência do pensamento. Nesses termos, a autonomia passa a significar não muito mais do que "começar a se vestir sozinho", "escovar os dentes sozinho", "comer de garfo e faca", "descascar uma banana”, "comer sem se sujar". Se pensarmos na tradição dos ideais de formação - autorreflexão crítica e não-identificação com o meramente existente, nos termos de Adorno (2000) -, temos, nesse contexto, uma visão reducionista de autonomia, que passa a ser sinônimo de domínio técnico de si e da vida.

Os esquemas da indústria cultural aparecem aqui como face do higienismo, como na maquiagem e na perfumaria, nos tênis e nas mochi- 
las, nas tatuagens e nos bonés, especialmente aqueles originalmente utilizados por esportistas, cantores/as ou atores/as que personificam a imagem do belo e do exemplar, da dedicação e da pureza, enfim, que representam não somente uma aparência saudável, mas também a saúde da conduta-mesmo na aparente transgressão -, compondo, assim, ideais estéticos e comportamentais que os pequenos não podem deixar de in-corporar.

As crianças interrompem suas atividades para mostrar seus corpos enfeitados com marcas e figuras de personagens midiáticos intercambiáveis, como são os produtos imiscuídos nos esquemas da indústria cultural, território no qual a fungibilidade universal encontra solo fértil. Presas a satisfações imediatas e exteriores, suas identidades vão se constituindo enquanto revelam, com entusiasmo: "Olha minha mochila da [...]", "Olha minha bota da [...]", "Olha minha tatuagem do [...]". Exibem, sem nenhum movimento de resistência e como parte de si mesmas ${ }^{10}$, os objetos consumidos. As crianças anunciam suas representações acerca da sobrevalorização da aparência quando chegam à creche e imediatamente apontam não apenas o objeto novo, mas seu emblema: o logotipo que sugere também a marca da personalidade do sujeito que vai se constituindo e encontrando a "felicidade" na mercadoria (TÜRCKE, 2001).

Tudo isso aparece relacionado ao propósito de encaminhar os pequenos na direção de uma gestão futura do corpo particular que se resume no consumo, se considerarmos cada corpo infantil que frequenta campos educacionais, tal como o da creche pesquisada: necessidades básicas (exigidas por legislação) supridas, aliadas à aprendizagem do autocontrole e da conservação física. Ou seja, fazer exclusivamente da atividade do labor o que resta da sua "condição humana". As crianças devem adormecer "logo" - como lhes explicam as professoras, para que não percam o horário do lanche; devem aproveitar todo o alimento, "para ter força para brincar no parque"; precisam comer "feijão para ter músculos para escalarem os brinquedos do parque". Enfim, nutrir-se para sobreviver. Parece-nos, pois, que esse círculo repetitivo de ações compreende um conjunto de exigências em torno da vida nua, com vistas à manutenção dessa mesma vida nua.

Mas essa vida insacrificável - porque matável, nos termos propostos por Giorgio Agamben (2004) - é preservada no sacrifício do eu, o que nos faz lembrar Horkheimer e Adorno (1985, p. 61) ao explicitarem que "a anti-razão do capitalismo totalitário, cuja técnica de satisfazer necessi- 
dades, [...] determinada pela dominação, torna impossível a satisfação das necessidades e impele ao extermínio dos homens - essa anti-razão está desenvolvida na maneira prototípica no herói, que se furta ao sacrifício sacrificando-se”. Quem sabe pudéssemos dizer que, tal como Ulisses ${ }^{11}$, personagem da Odisséia, que anulou-se ao nomear-se Ninguém, fazendose desaparecer no logro para salvar a própria vida ${ }^{12}$, as crianças também reneguem a si mesmas em favor da conservação: "preservam a vida por uma imitação mimética do amorfo". Diferentemente de Ulisses, portador da astúcia e tecnicamente esclarecido, que salva a vida ao deliberadamente vestir a máscara do nada, mas que restaura a própria identidade ao revelar seu verdadeiro nome durante a fuga, a criança ainda não compreende o nominalismo, sendo incapaz de inscrever uma intenção ao nome e não reconhecendo o poderio da palavra sobre as coisas. Ela permanece presa ao círculo das necessidades, o que reforçará a impossibilidade de ultrapassar aquele limiar de indistinção entre norma e vida biológica.

Observamos, assim, uma pedagogia da infância atuando, ao lado de plurais higienismos, como braço pedagógico da biopolítica. Essa pedagogia se instaura, para além das práticas de assepsia, no controle do corpo, na tentativa de aniquilação do desejo, na proibição; dirige-se, no limite, à imitação do que está morto, mimesis da morte, ao mesmo tempo em que mantém vivos os indivíduos. Ela não se reduz aos períodos demarcados para higiene no interior da rotina: acompanha, atravessa os tempos, espaços, atividades do dia a dia da creche, reunindo práticas que se estabelecem de modo contínuo e invariável. Isso também pode ser observado nas palavras dos/das professores/as, quando se encontram em sala: "vamos levar (as crianças) para fora (pátio), senão elas vão mofar". Ou durante os momentos de alimentação, quando, ao servir os pequenos, também "servem" sucessiva e ininterruptamente expressões tais como: "Chuchu é bom pra ficar forte"; "Só vou dar o prato para quem estiver sentadinho"; "Que adulto (!), comendo de faca!"; "Come tudo para ter força para brincar no parque"; "Tudo mocinha grande, rapazinho grande, fazer essa imundície toda... Onde já se viu?"

Também as aulas de Educação Física contribuem para a produção da vida nua, mesmo que como promotoras da saúde, conformando aquela circulação de saberes relacionados aos preceitos da higiene, como se pode observar nessa cena recortada de nosso diário de campo: 
Em sala, a professora e a auxiliar penteiam as crianças, enfeitam as meninas com pregadores de cabelo e mandam que se sentem sobre o tapete. [...] Uma criança se aproxima e mostra seus tênis "de luzinha" [...] Um menino retorna do banheiro com o cabelo molhado. A professora grita: "Não é para molhar o cabelo com água fria. Depois vai ficar com dor de ouvido. Depois vai para a rua na Educação Física com cabelo molhado..." [...] Às 14h, a professora de Educação Física entra e diz: "Vamos, turma!" Sai e as crianças a seguem até o terreno da horta. Solicita que cada criança se acomode sobre uma das várias pedras ali dispostas em círculo. Em seguida, convida as crianças a "tirarem a preguiça" por meio da imitação dos gestos relacionados à canção cujo tema é "banho é bom". Então a professora avisa às crianças que, ao utilizarem os brinquedos, eles também devem ser guardados. [...] Uma criança se aproxima e diz que não gosta de brincar nesse terreno "porque pega espinho no tênis de luzinha”. Um garoto ultrapassa a cerca (em precárias condições) e a professora adverte: "Quer voltar para a sala?” Sobre a árvore os meninos gritam: "Socorro, furacão!", e pulam de seus galhos. A professora se aproxima da árvore [...] e avisa: "Cuidado para não sujar, senão as professoras lá da sala vão ficar doidas" [...] Já na roda, a professora destaca que há crianças que não escutam, que ela fica "chamando" e "o horário já terminou". Segue: "Quantas vezes chamei para fazer brincadeira e ninguém colaborou?!” [...] A auxiliar toma a palavra e diz: "Estamos atrasados. Agora nós vamos lavar as mãos com cuidado que as tias já lavaram o banheiro, e depois vamos lanchar".

A cena anuncia a expressão de preconceitos, de uma tremenda resistência contra tudo o que possa mostrar ou lembrar mistura e diferença. Ou, de outro modo, contra aquilo a que somos obrigados a renunciar a fim de nos reconhecermos humanos, civilizados. Se, por um lado, a civilização exige renúncias que permitem que sigamos vivendo em sociedade, por outro, os sacrifícios que se impõem nesse sentido permanecem como uma expressão do mal-estar da cultura.

Esse processo de domínio-repulsão do corpo, de sacrifícios internalizados, de negação e repressão, parece fazer-se presente na creche, muitas vezes, de modo duro, dolorido, rígido, isento de entendimento, de interpretação ${ }^{13}$. Essa dureza pode significar uma indiferença à dor que permite ao agredido transformar-se em agressor, "vingando-se da dor que precisou ocultar ou reprimir" (ADORNO, 2000 p. 128).

No esforço - e na violência, muitas vezes empregada nas palavras gritadas pelos adultos - em manter as crianças "não sujas", "não fedidas", "não podres", "cheirosas", como dizem as professoras, talvez sobreviva o medo 
da sedução da diluição do sujeito à antiga nostalgia pelas formas inferiores de vida, pela união imediata com a natureza ambiente, com a terra, com o barro. De todos os sentidos, o ato de cheirar [...] é o testemunho mais evidente da ânsia de se perder no outro e com ele se identificar. Por isso o cheiro, tanto como percepção e quanto como percebido, (ambos se identificam no ato) é mais expressivo do que os outros sentidos. Ao ver, a gente permanece quem a gente é, ao cheirar a gente se deixa absorver. [...] O impulso recusado é permitido na medida em que o civilizado desinfeta através de sua identificação incondicional com a instância recusadora. [...] Os impulsos que o sujeito não admite como seus e que, no entanto, lhe pertencem são atribuídos ao objeto, a vítima em potencial. (HORKHEIMER; ADORNO, 1985, p. 171).

\section{Palavras finais}

Todo o rigor que busca favorecer o bem-estar físico individual e a saúde dos indivíduos que convivem no espaço da creche sugere uma vinculação simultânea aos processos de individuação e totalização, pautando-se na potencialização da vida meramente biológica e, ao mesmo tempo, na civilização da conduta de cada indivíduo em particular.

O corpo infantil doente ou acamado e a carência econômica aparecem tanto na história da educação infantil brasileira quanto na história e na atualidade da instituição pesquisada, de modo indissociável. Noutras palavras, doença e pobreza são inseparáveis nos programas de assepsia, nos higienismos passados e contemporâneos, dissimulados e latentes que marcam os processos educativos. Talvez possamos dizer que as concepções higienistas do século XIX e seus pressupostos governem ainda o mundo contemporâneo, os corpos, os sentidos e, sob novas nomenclaturas e configurações, permaneçam atuando junto à produção não tanto da qualidade de vida, mas da vida qualificável em sentido muito particular, tomada de atributos e classificações, modelos e normas, estilos examináveis e quantificáveis. Destaque-se novamente que o desvio da norma(l) aparece como patologia que deve ser "erradicada". Diferentes ou desviantes podem facilmente ser remetidos ao campo dos inimigos, podem ser (ou manter-se) excluídos. Vale recordar as palavras de Adorno ao explicitar que a capacidade de perceber o outro enquanto tal é substituída, na experiência limítrofe do fascismo - mas cuja diferença das democracias contemporâneas é apenas de grau e não de natureza (ADORNO; HORHEIMER, 1985) -, por um conhecimento avaliativo dos homens, por 
um olhar fixo que examina, fascinante e fascinado, e que é próprio de todos os líderes [Führer] do terror. [...] As palavras do Novo Testamento, 'quem não está comigo, está contra mim’, são palavras que sempre vieram do fundo do coração do anti-semitismo. Um dos elementos básicos da dominação é remeter ao campo dos inimigos por causa da simples diferença todo aquele que não se identifica com ela. [...] Carl Schmitt definia a essência do que é político diretamente pelas categorias amigo-inimigo. O progresso em direção a tal consciência faz a sua regressão ao modo de comportamento da criança que ou gosta de uma coisa ou a teme. [...] A liberdade seria não a de escolher entre preto e branco, mas a de escapar à prescrição de semelhante escolha (ADORNO, 1993, p. 115).

O conjunto de concepções e práticas sócio-sanitárias que contribuem para a eliminação de desvios e diferenças, na conformação e na potencialização daquelas pequenas vidas, parece operar como braço pedagógico da biopolítica, promovendo, sob o jugo dos saberes científicos e de seus agentes (professores/as, merendeiras, serventes, nutricionistas, etc.), a medicalização da vida e da condição social, tratando meramente das necessidades vitais e assegurando pseudogratificações. Enfim, concentrando-se na esfera biológica, nas necessidades vitais, a educação e o cuidado na creche acabam consagrando o predomínio do consumo, do labor, antes mesmo que os pequenos possam alcançar sua condição de sujeitos políticos. Trata-se, nos termos de Arendt (2002), do reducionismo da condição humana, naquele espaço que deveria promover a experiência formativa, ao estado de Animal laborans.

A rotina higiênica da creche corre de modo circular, tal como o hábito de reunir as crianças em círculo nas aulas de Educação Física e nas atividades realizadas em sala. Essa roda lembra a repetição que procura, paranoica, a rígida disciplina contra a ameaça do indeterminado. No limite, ao permanecer num ciclo de satisfação das necessidades, temos uma produção de corpos sem experiência e história, com a memória sequestrada, retornando, sempre novamente, ao reino da inércia, ao estado de repouso, apesar do movimento: temos a morte, o regresso a um estado anterior, tal como o vivem os que se alimentam com a comida oferecida pelos comedores de lótus, alimento cujo poder é a condenação ao esquecimento e à destruição da vontade. Ou seja, ficar por ali, comendo, vivendo, na impossibilidade de construir uma experiência, sem recordação, memória.

A rotina $\mathrm{da} / \mathrm{na}$ creche acaba, assim, por operar sobre uma infância nua na qual se atribuem qualificações, tais como aquelas que vigoraram 
e vigoram com as concepções higienistas dos séculos passados: pequenos limpos, saudáveis, nutridos, enfeitados, cheirosos. Essas crianças que a frequentam talvez não morram por desnutrição, obesidade, doenças infectocontagiosas. A instituição e seus agentes auxiliam na diminuição das taxas de mortalidade por doenças, criando sobreviventes. Mas isso não impede que essa vida seja matável. Embora livres de doenças infecto-contagiosas, esses pequenos podem ser eliminados como aqueles que compõem turbas ou bandos, incluídos-excluídos, marginalizados que a própria sociedade produz. Por outro lado, já estão eliminados da possibilidade do alcance de uma posição de sujeitos políticos, visto que, em tempos de biopolítica (e de experiência expropriada), a ação humana não tem voz, encontrando-se encolhida como elemento de nossa condição bumana.

\section{Notas}

${ }^{1}$ O presente texto é resultado parcial do projeto Teoria Crítica, Racionalidades e Educação II, financiado pelo CNPq (Auxílio pesquisa, bolsas de produtividade em pesquisa, apoio técnico à pesquisa, doutorado, mestrado e iniciação científica). Os autores agradecem a leitura e contribuições de Jaison José Bassani e dos pareceristas da Educação em Revista.

Hannah Arendt (2002) analisa as três atividades que integram a condição humana: o labor, o trabalho e a ação. O trabalho do Homo faber produz um mundo artificial de coisas, cria um mundo comum de significações que possibilitam ao sujeito dar um sentido à própria existência; a ação é a condição da vida política e corresponde à condição humana da pluralidade: a capacidade de agir, de expressar as singularidades, introduzir seus saberes no espaço vivente e começar algo novo, responsabilizando-se pelo mundo público comum. Diferentemente do trabalho e da ação, o labor é uma atividade ligada ao processo biológico. A vida do Animal laborans está ligada aos processos vitais, ao que se consome no próprio metabolismo, à conservação física e àquela manutenção e preservação da vida de que os homens e os animais comungam.

${ }^{3}$ Vale citar Verdi (2002, p. 166), segundo a qual, ao longo da história do Brasil, foram e são empreendidas políticas ligadas aos hábitos de vida, à "qualidade de vida", "tratando da enfermidade e pobreza como inseparáveis". Trata-se, segundo a autora, de "higienismos no plural".

${ }^{4}$ Paulatinamente, as creches e pré-escolas vêm atendendo crianças até os 5 anos de idade, dada a nova legislação educacional brasileira, que regulamenta o Ensino Fundamental de 9 anos, a Lei 11.274/2006.

${ }^{5}$ Em Foucault (1999), o termo biopolítica designa uma transformação no modo como o poder vai sendo exercido, passando não apenas a governar os indivíduos por meio de disciplinas, mas tomando como foco a população ou o corpo-espécie. Alicerçado em Foucault, Giorgio Agamben (2004) explica que a vida biológica, o corpo-espécie, a vida 
nua ou o simples fato de viver que os homens e os animais comungam, tornam-se alvo da forma dominante da política ocidental. Nesse quadro, a biopolítica, conforme já apontara Foucault (2008), move-se em direção à tutela da vida do conjunto de uma população. 6

Apoiamo-nos aqui em Agamben (2004), fortemente alicerçado em Foucault (1999), para quem a norma, entre outros aspectos, "a partir da valorização das condutas, impõe uma conformidade que se deve alcançar; busca homogeneizar” (CASTRO, 2009, p. 310). A norma "traça a fronteira do que lhe é exterior (a diferença com respeito a todas as diferenças), a anormalidade" (CASTRO, 2009, p. 310).

Segundo Bassani e Vaz (2003, p. 2), podemos considerar a existência de uma "pedagogia do corpo na sociedade contemporânea, que se organizaria de forma complexa, contraditória, mas também coerente, estruturando-se em vários ambientes educacionais: na escola, nas academias de ginástica e musculação, na cultura corporal popular (capoeira), na cultura corporal erudita (balé), entre outros. Essa pedagogia se vale de um conjunto de técnicas e especialistas, como professores de Educação Física, nutricionistas, cirurgiões plásticos, pedagogos, etc. Ela tem também suas cartilhas - como as revistas ilustradas -, suas disposições "científicas" e, sobretudo, os produtos que devem ser consumidos para que se eduque o corpo. A pedagogia do corpo, que elabora predições diferentes para jovens e idosos, crianças e adultos, homens e mulheres, eficientes e deficientes, diz como o corpo e o sujeito não podem deixar de ser".

${ }^{8}$ Comparados aos piolhos e outros bichos abjetos, os judeus deveriam ser eliminados. A transformação das pessoas em animais aparece nos contos infantis como castigo e equivale, segundo Horkheimer e Adorno, (1985, p. 230-231) a uma condenação: "Para as crianças e os diferentes povos, a idéia de semelhantes metamorfoses é imediatamente compreensível e familiar". É possível identificar, seja nas vozes das professoras seja nos gestos velozes e nos objetos por meio dos quais estabelecem mediações com as crianças, como, por exemplo, o uso de luvas, sentimentos de asco direcionados ao controle da sujidade, essa irracionalidade, inferioridade biológica, reconhecida nos animais, nas crianças, nas mulheres, nos loucos, nas criaturas mais próximas à natureza, mais miméticas. Sentimentos que talvez representem o pavor diante do retorno ao primitivo, àquilo que renunciamos, às pulsões que, de forma obscurecida, expressam a natureza não racional. Benjamin, no aforismo Luvas (2000, p. 16-17), escreve: "No asco por animais a sensação dominante é o medo de, no contato, ser reconhecido por eles. O que se assusta profundamente no homem é a consciência obscura de que, nele, permanece em vida algo de tão pouco alheio ao animal provocador de asco, que possa ser reconhecido por este. [...] Não lhe é permitido renegar o bestial parentesco com a criatura, a cujo apelo seu asco responde: é preciso tornar-se senhor dela".

"O esporte não aparece em sua "forma pura", mas como estrutura modelar e exemplo de uma civilização que acredita, fascinada, no progresso linear e infinito.

10

De outro modo, ainda nesse conjunto de processos sócio-sanitários, colocam-se elementos que, contemporaneamente, também atuam como normas que favorecem processos de exclusão. Isso pode ser observado numa cena extraída de nosso diário de campo, segundo o qual um grupo de meninas permitia a entrada de outras crianças no espaço da brincadeira somente se estivessem com as bocas devidamente pintadas com batom. 
11

Na relação com o sacrifício, o Homo sacer parece aparentear-se com Ulisses, herói da narrativa homérica, tomado por Horkheimer e Adorno como alegoria do processo de constituição do homem no sentido moderno, ou seja, racional e esclarecido: "O domínio do homem sobre si mesmo, em que se funda todo seu ser, é sempre uma destruição virtual do sujeito a serviço do qual ele ocorre, pois a substância dominada, oprimida e dissolvida pela autoconservação, nada mais é senão o ser vivo, cujas funções configuram, elas tão somente, as atividades de autoconservação, por conseguinte exatamente aquilo que na verdade deveria ser conservado. [...] A história da civilização é a história da renuncia. Quem pratica a renúncia dá mais de sua vida do que lhe é restituído, mais do que a vida que ele defende. [...] Uma vítima de um desses sacrifícios é o próprio Ulisses, o eu que está sempre a se refrear e assim deixa escapar a vida que salvou..." (HORKHEIMER; ADORNO, 1985, p. 61).

${ }^{12} \mathrm{Na}$ Odisséia de Homero (2002), Ulisses enfrenta nove episódios, entre os quais a luta contra Polifermo, um ciclope gigante de olho só que aprisiona Ulisses e seus companheiros numa caverna. Enquanto são devorados, Ulisses oferece-lhe vinho e diz ao Gigante que seu nome é Ninguém. Certa noite, Ulisses fura o olho do gigante, que, urrando de dor, pede socorro aos habitantes da ilha. Ao ser indagado pelo motivo, Polifermo grita que "ninguém" o atacara. Nesse caso, é-lhe dito, seria então obra da mão divina e que a ele restaria a resignação. Ulisses e alguns companheiros ainda vivos escaparam da caverna e, já em alto mar, o comandante chama Polifermo a fim de revelar seu nome. Esse ato quase não os permite escapar das pedras então lançadas pelo monstro. Noutro episódio, Ulisses e seus companheiros são lançados pelos ventos à terra dos Lotófagos, cujos habitantes ofereciam o lótus, planta que lhes faria perder a memória e os condenaria a ali permanecerem, para sempre. No entanto, Ulisses os retirou rapidamente do local, não sem que houvesse consequências no prosseguimento da viagem.

13

Há que se destacar a presença de relações outras com o corpo, tal como a cena em que, vagarosamente, a professora banha a menina, deslocando o fluxo do tempo para a “delícia da água quentinha”, da água morna que toca a pequena e suas próprias mãos. Constroem-se outras formas de comunicação que não aquela marcada pela brevidade, pela velocidade, ou meramente regulada por interesses práticos.

\section{Referências bibliográficas}

ADORNO, T. Educação e emancipação. 2 ed. São Paulo: Paz e Terra, 2000.

ADORNO, T. Minima Moralia: reflexões sobre a vida danificada. 2 ed. São Paulo: Ática, 1993.

AGAMBEN, G. Homo Sacer: o poder soberano e vida nua. Belo Horizonte: UFMG, 2004.

ARENDT, H. A condição bumana. 10 ed. Rio de Janeiro: Forense Universitária, 2002.

BASSANI, J. J.; VAZ, A. F. Educação do corpo e auto-reflexão crítica: uma investigação na dimensão pedagógica da obra de Theodor W. Adorno. In: XIII Congresso Brasileiro de Ciências do Esporte, 2003, Caxambú. Anais. Campinas: CBCE, 2003.

BENJAMIN, W. Obras escolhidas II: rua de mão única. 4 ed. São Paulo: Brasiliense, 2000. 
BRASIL. Ministério da Educação e do Desporto. Secretaria de Educação Fundamental. Referencial curricular nacional para educação infantil. Brasília: MEC/SEF, 1998. 3v.

CASTRO, E. Vocabulário de Foucault: um percurso pelos seus temas, conceitos e autores. Belo Horizonte: Autêntica, 2009.

COOPER, C. L. F; SAYD. J. D. Concepções de Saúde nos Parâmetros Curriculares Nacionais. In: BAGRICHEVSKY, M. et.al (Org.). A saúde em debate na Educação Física. Blumenau: Nova Letra, 2006. P. 179-200.

COSTA, J. F. da. Ordem médica e norma familiar. 4 ed. Rio de Janeiro: Graal, 1999.

ELIAS, N. O processo civilizador: uma história dos costumes. Rio de Janeiro: Jorge Zahar, v.1. 1994.

FOUCALT, M. O nascimento da biopolítica. São Paulo: Martins Fontes, 2008.

FOUCALT, M. Em defesa da Sociedade. São Paulo: Martins Fontes, 1999. p. 285-315.

GONDRA, J. G. A sementeira do porvir: higiene e infância no século XIX. Educação e. Pesquisa, São Paulo, v. 26, n. 1, p. 99-117, jan./jun. 2000.

HOMERO. Odisséia. São Paulo: Martin Claret, 2002.

HORKHEIMER, M.; ADORNO, T. W. Dialética do esclarecimento: fragmentos filosóficos. Rio de Janeiro: Zahar, 1985.

KUHLMANN Jr., M. Infância e educação infantil: uma abordagem histórica. Porto Alegre: Mediação, 1998.

MINAYO, C. Saúde como responsabilidade cidadã. In: BAGRICHEVSKY, M. et.al (Org.). A saúde em debate na Educação Física. Blumenau: Nova Letra, 2006. p. 93-102.

OLIVEIRA, S. M. de. Qualidade de vida, corpos aprisionados. In: BAGRICHEVSKY, M.; et.al. (Org.). A saúde em debate na educação física. Blumenau: Edibes, 2003. p. 99-114. OSTETTTO, L. E. Educação infantil em Florianópolis. Florianópolis: Cidade Futura, 2000. TÜRCKE. C. A Luta pelo Logotipo. Trad. Peter Naumann. In: DUARTE, R.; FIGUEIREDO, V. (Orgs.) Mimesis e Expressão. Belo Horizonte: Humanitas, 2001.

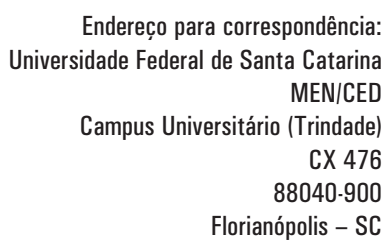

Data de recebimento: 12/08/2008

Data de aprovação: 06/11/2009 